\title{
A comparative cytogenetic analysis between the grasshopper species Chromacris nuptialis and C. speciosa (Romaleidae): constitutive heterochromatin variability and rDNA sites
}

\author{
Vilma Loreto ${ }^{1, \dagger}$, Eva Stadtler ${ }^{1}$, Natoniel F. de Melo $^{2} \&$ Maria José de Souza ${ }^{1}$ \\ 'Departamento de Genética, CCB, Universidade Federal de Pernambuco (Phone: + 55-81-2126-8520; E-mail: \\ vloreto@zipmail.com.br), ${ }^{2}$ Embrapa Semi-árido, Petrolina, Brasil, ${ }^{\dagger}$ Av. Prof. Moraes Rego s/n Cidade \\ Universitária, Recife, PE, 50732-970, Brasil
}

Received 3 April 2005 Accepted 23 June 2005

Key words: FISH, grasshopper, heterochromatin, karyotype, NORs

\begin{abstract}
The chromosomes of Chromacris nuptialis and $C$. speciosa were comparatively analyzed using different cytogenetic techniques, in order to determine the level of karyotypic similarities and differences between the species. The results show similarities in chromosome number $(2 n=23, \mathrm{X} 0)$ and acrocentric morphology. In some $C$. nuptialis individuals meiotic irregularities were detected involving the $\mathrm{L}_{2}$ bivalent. This bivalent was delayed and presented anaphasic bridges and other aberrations. Differences in constitutive heterochromatin $(\mathrm{CH})$ patterns and composition were observed through $\mathrm{C}$-banding and fluorochromes staining. Silver nitrate staining revealed a single medium nucleolar organizer regions (NORs) pair, per species. Differences were also observed in NORs location, which was pericentromeric in C.nuptialis and proximal in C.speciosa. FISH using an rDNA probe confirmed the existence of ribosomal sites coinciding with active regions visualized by silver nitrate. The possible implications of the karyotype differences observed between both species are discussed.
\end{abstract}

\section{Introduction}

Grasshoppers of the genus Chromacris are restricted to the Neotropical region and are found from Mexico to Argentina. These insects present strong colors with yellow or red stains, on their wings. Based on those characteristics, Roberts and Carbonell (1982) divided the genus Chromacris in two groups: one called trogon, that includes $C$. trogon, $C$. psittacus, $C$. icterus and $C$. peruviana, and another called colorata that consists of $C$. colorata, C. minuta, C. miles, $C$. speciosa and $C$. nuptialis. The latter taxon is related to C. speciosa, which was initially considered to be a variant form. However, the study of some morphological traits has indicated that it is a distinct species (Roberts \& Carbonell, 1982).

Romaleidae family has shown a marked predominance of conserved karyotypes $(2 n=23,24$
X0:XX) (Mesa, Ferreira \& Carbonell, 1982). Nevertheless, analysis of constitutive heterochromatin (CH) by $\mathrm{C}$-banding has revealed both variations in terms of the quantity and location of $\mathrm{CH}$ blocks, among different species. Pericentromeric location has been the most frequent having been observed in seven out of eight species studied so far (Vilardi, 1986; Souza \& Kido, 1995; Pereira \& Souza, 2000; Souza, Haver \& Melo, 2003). Additionaly, ocurrence of interstitial and distal blocks has been reported for Xyleus angulatus (Souza \& Kido, 1995; Souza, Rufas \& Orellana, 1998), Radacridium mariajoseae, $R$. nordestinum (Rocha, Souza \& Tashiro, 1997), and Chromacris speciosa (Souza \& Kido, 1995). Polymorphisms for supernumerary heterochromatic segments have been described for $X$. angulatus (Souza \& Silva-Filha, 1993) and $R$. nordestinum (Rocha, Souza \& Tashiro, 1997) and B chromosomes have been observed in $X$. angulatus

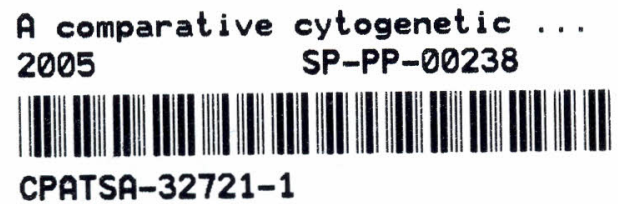

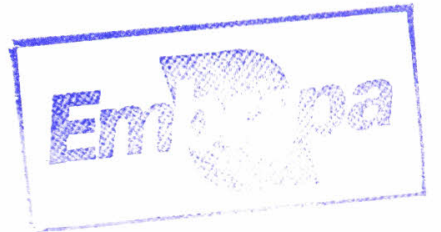


(Souza \& Kido, 1995) and Zoniopoda tarsata (Vilardi, 1986), proving the intensive variability in $\mathrm{CH}$, among representatives of this family.

As to cytogenetic characteristics, knowledge about the genus Chromacris is limited to the studies of Mesa, Ferreira and Carbonell (1982) who described the karyotype of three species ( $C$. speciosa, C. peruviana and C. miles) as $2 n=23, \mathrm{X} 0$ and $2 n=24, X X$ and Souza and Kido (1995) that analyzed the variability in $\mathrm{CH}$ distribution in $C$. speciosa by C-banding.

Some studies have shown that comparative cytogenetic analysis of grasshoppers can contribute to the understanding of the speciation process (Bella et al., 1990). Bridle et al. (2002) emphasized the close karyotype similarity between Chorthippus brunneus and $C$. jacobsi, when analyzing $\mathrm{C}$-banding patterns and $\mathrm{CH}$ composition by fluorochrome labeling. However, Rodríguez-Iñigo, Bella and García de la Vega (1993), analyzing two species of the genus Dociostaurus, and Camacho and Cabrero (1983), analyzing the species Acrotylus insubricus and $A$. patruelis, showed differences in the patterns and composition of $\mathrm{CH}$ between related species, indicating that both loss or acquisition of heterochromatin might be involved in karyotype evolution.

In the present study, we performed a comparative cytogenetic analysis between $C$. nuptialis and C. speciosa by conventional analysis, C-banding, fluorochrome and silver nitrate staining, and fluorescence in situ hybridization (FISH) using a $45 \mathrm{~S}$ rDNA probe, in order to determine the level of similarities and differences between these species.

\section{Material and methods}

A total of 16 adult male specimens of $C$. nuptialis collected in the locality of Exu $\left(7^{\circ} 26^{\prime} 0^{\prime \prime} \mathrm{S}\right.$ $39^{\circ} 50^{\prime} 36^{\prime \prime} \mathrm{W}$ ) and 25 specimens of C. speciosa collected in Moreno $\left(8^{\circ} 7^{\prime} 7^{\prime \prime}\right.$ S $\left.35^{\circ} 5^{\prime} 32^{\prime \prime} \mathrm{W}\right)(15$ males and 3 females) and Igarassú $\left(7^{\circ} 50^{\prime} 3^{\prime \prime} \mathrm{S}\right.$ $34^{\circ} 54^{\prime} 23^{\prime \prime} \mathrm{W}$ ) (5 males and 2 females), State of Pernambuco, Brazil, were studied. The grasshoppers were brought to the laboratory, dissected and the testes and ovaries were fixed in ethanol:acetic acid $(3: 1)$. Females were injected with $0.1 \%$ colchicine for $6 \mathrm{~h}$. Slides were prepared using the classical testicular and ovarian follicles squashing technique, followed by staining with $2 \%$ lacto- acetic orcein for conventional chromosome analysis. For the different banding techniques, the slides were prepared by the addition of one drop of $45 \%$ acetic acid and were covered with coverslips that were removed after freezing in liquid nitrogen.

\section{$C$-banding and $C M A_{3} / D A / D A P I$ staining}

C-banding was performed according to Sumner (1972). Slides aged for 2 days were treated with $0.2 \mathrm{~N} \mathrm{HCl}$ for $30 \mathrm{~min}, 5 \%$ barium hydroxide $\left(60^{\circ} \mathrm{C}\right)$ for $45 \mathrm{~s}$, and $2 \times \mathrm{SSC}\left(60^{\circ} \mathrm{C}\right)$ for $45 \mathrm{~min}$. After drying, the preparations were stained with Giemsa $5 \%$ diluted in phosphate buffer, $\mathrm{pH} 7.0$, for $3 \mathrm{~min}$. For $\mathrm{CMA}_{3} / \mathrm{DA} / \mathrm{DAPI}$ staining (Schweizer et al., 1983), the slides were aged for 3 days, stained with $\mathrm{CMA}_{3}$ $(0.5 \mathrm{mg} / \mathrm{ml}$ in Mcllvaine buffer, $\mathrm{pH} 7.0)$ for $1 \mathrm{~h}$, washed in distilled water, stained with Distamycin A (DA) $(0.1 \mathrm{mg} / \mathrm{ml})$ for $45 \mathrm{~min}$, washed again, and stained with DAPI $(0.5 \mu \mathrm{g} / \mathrm{ml})$ for $20 \mathrm{~min}$.

Silver nitrate staining $\left(\mathrm{AgNO}_{3}\right)$ and fluorescence in situ hybridization (FISH)

Cytological preparations were pretreated with $2 \times$ SSC at $60^{\circ} \mathrm{C}$ for $10 \mathrm{~min}$, washed, dried, stained with one drop of $\mathrm{AgNO}_{3}$ solution (1:1) in distilled water (with the $\mathrm{pH}$ adjusted with formic acid), and then incubated in a humid chamber at $70^{\circ} \mathrm{C}$ for 3 min (Rufas, Esponda \& Gosálvez, 1985). Some preparations were counterstained with Giemsa before mounting.

For FISH, a probe containing fragments of the $45 \mathrm{~S}$ ribosomal genes (18S-5.8S-25S) of Arabidopsis thaliana (Unfried, Stocker \& Gruendler, 1989; Unfried \& Gruendler, 1990) was used to localize rDNA sequences. The probe was labeled with biotin-11-dUTP by nick translation, and the preparations were incubated with RNAse, proteinase $\mathrm{K}, \mathrm{MgCl}_{2} / \mathrm{PBS}$ and paraformaldehyde/PBS solutions, and finally dehydrated in an increasing alcohol series $(70-90-100 \%, 5 \mathrm{~min}$ each) according to Moscone, Matzke and Matzke (1996). Hybridization was performed at $80^{\circ} \mathrm{C}$ using $5 \mu \mathrm{l}$ of the mixture. The slides were kept at $37^{\circ} \mathrm{C}$ overnight for renaturation. The probe was detected with an anti-biotin-rhodamine antibody. The chromosomes were counterstained with DAPI and the slides were mounted in Antifade Vectashield (Vector) medium. 
Photographs were taken with a Leica microscope using Kodak ISO 25 films, TMAX-400 and Fuji Film ISO-400 for FISH, and printed on Kodak Kodabrome Print F3 paper.

\section{Results}

The diploid number of Chromacris speciosa and C. nuptialis was $2 n=23, \mathrm{X} 0$, in males and $2 n=24, X X$, in females. Both species present acrocentric chromosomes which were grouped in two large sized one $\left(\mathrm{L}_{1}-\mathrm{L}_{2}\right)$, six medium $\left(\mathrm{M}_{3}-\mathrm{M}_{8}\right)$ and three small pairs $\left(\mathrm{S}_{9}-\mathrm{S}_{11}\right)$. The $\mathrm{X}$ chromosome was medium sized (Figure 1a-f). In both species, the $\mathrm{X}$ presented a variable heteropycnotic behavior, positive from leptotene to diplotene and negative during diakinesis and metaphase I (Figure $1 \mathrm{a}-\mathrm{c}$ ).

Our cytogenetics studies in the 16 individuals of $C$. nuptialis confirmed that six of them have meiotic irregularities likely the stickiness. The $\mathrm{L}_{2}$ pair presented anaphasic delay and atypic bridges formation through the union of the homologous chromatids, in terminal position (Figure $2 \mathrm{a}-\mathrm{b}$ ). In that region a block of constitutive heterochromatin $(\mathrm{CH})$ was observed close to the sticky point (Figure 2b). In some cells the behavior of the laggard pair may indicate that it has not been incorporated to the new formed nucleus (Figure 2c). The presence of chromosomal fragments (Figure 2d) might have originated from the separation of telophasic cells (a)

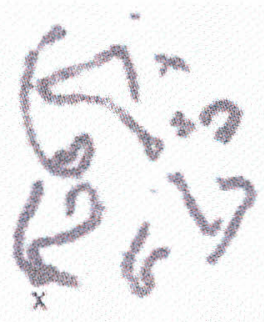

(c)

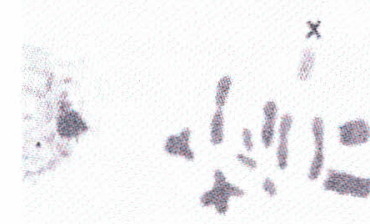

(e) (b)

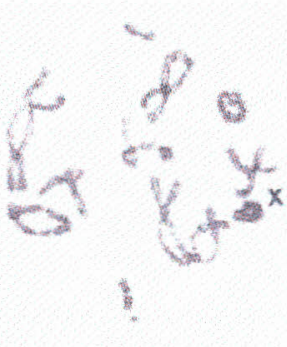

(d)

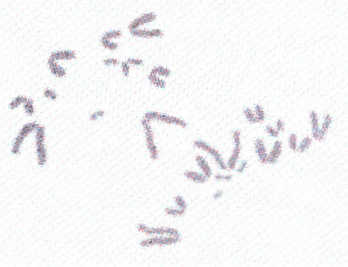

(f)

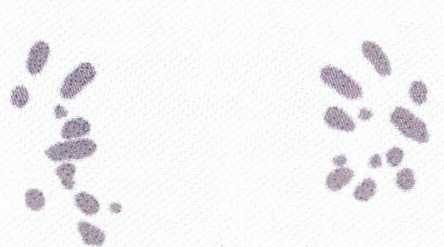

Figure 1. Meiotic cells of Chromacris muptialis (a,b,d,f) and C. speriosa (c and e). (a) Pachytene, (b) Diplotene, (c) Metaphase I, (d) Anaphase I, (e) Metaphase II with 11 chromosomes, and (f) Anaphase II with 12 chromosomes. Note the X chromosome heteropycnotic positive ( $\mathrm{a}$ and $\mathrm{b}$ ) and negative (c). Bar $=10 \mu \mathrm{m}$. 
(a)

(c)

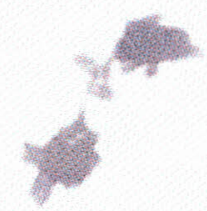

(b)

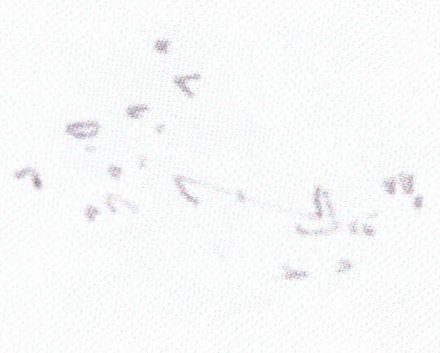

(d)

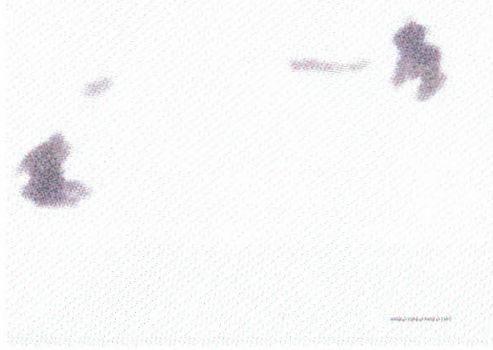

Figure 2. Irregularities in the meiosis I of $C$. nuptialis. ( $a$ and b) Anaphase showing the bridge formation among homologous chromatids of bivalent $\mathrm{L}_{2}$. Note in (b) the terminal block of $\mathrm{CH}$ in $\mathrm{L}_{2}$ (arrow). (c and d) Telophase showing the delayed pair and the union among chromatids resulting in fragments. Bar $=10 \mu \mathrm{m}$.

and the breaking of bridges. Out of the 647 cells in anaphase and telophase I from three individuals analyzed, $15(2.3 \%)$ presented bridge formation and $632(97.7 \%)$ were normal.

C-banding allowed the visualization of distinct $\mathrm{CH}$ distribution patterns in the two species. C. nuptialis exhibited $\mathrm{CH}$ blocks in the pericentromeric region of most chromosomes, while the small pairs presented variable $\mathrm{CH}$ blocks in location and size. It was visualized an interstitial, a telomeric and a small block and apparently pericentromeric in the $S_{9}, S_{10}$ and $S_{11}$ bivalents, respectively. A block was also observed in the telomeric region of the $\mathrm{L}_{2}$ pair (Figure $3 \mathrm{a}$ ).

On the other hand, C. speciosa, presented a highly variable $\mathrm{CH}$, in terms of size and block position. C-banding of mitotic metaphases revealed pericentromeric $\mathrm{CH}$ in all chromosomes. However, on $\mathbf{M}_{3}, \mathbf{M}_{4}, \mathrm{M}_{5}$ and $\mathrm{M}_{6}$ pairs $\mathrm{CH}$ blocks covered a marked portion of the proximal part of the long arm. A telomeric C-band was observed on the $L_{1}$ and $L_{2}$ pairs, and a large interstitial block was seen in the $\mathbf{M}_{8}$ pair. A small intersticial block was also noted on the $\mathbf{M}_{5}$ and $\mathbf{M}_{7}$ pairs, as well as in the $\mathrm{X}$ chromosome (Figure $3 \mathrm{c}$ ). This pattern was detected in meiotic cells (Figure 3b).

The $\mathrm{CMA}_{3} / \mathrm{DA} / \mathrm{DAPI}$ staining revealed different patterns in the species. Whereas C. nuptialis presented only one bivalent $\left(\mathrm{M}_{6}\right)$ with a $\mathrm{CMA}_{3}^{+}$ block in the pericentromeric region (Figure $3 \mathrm{~d}$ ), $\mathrm{C}$. speciosa had two $\mathrm{CMA}_{3}^{+}$blocks, one in the proximal portion of $\mathrm{M}_{6}$ and another in the telomeric region of $\mathrm{L}_{2}$ (Figure 3f). DAPI staining was homogenous in the two species (Figure 3e,g).

Silver nitrate staining identified only one NOR, in the medium pair $\left(\mathrm{M}_{6}\right)$ of both species (Figure 4a, c). In situ hybridization with the rDNA probe confirmed the existence of only one pair of ribosomal sites per species $\left(\mathbf{M}_{6}\right)$ and these sites were located in different regions of the chromosomes, with a pericentromeric location being observed for $C$. nuptialis (Figure $4 b$ ) and a proximal location for C. speciosa (Figure 4d). In both cases, the nucleolar organizer regions (NORs) coincided with the $\mathrm{CMA}_{3}^{+}$heterochromatin regions. 


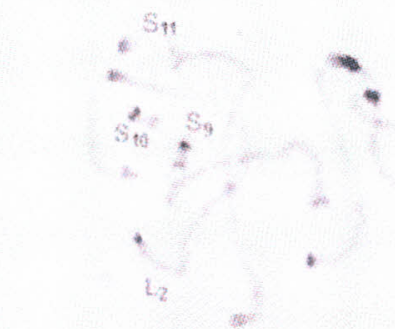

(a)

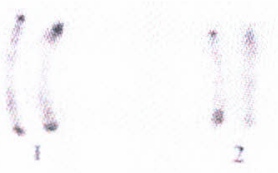

$$
1 .
$$

(c)
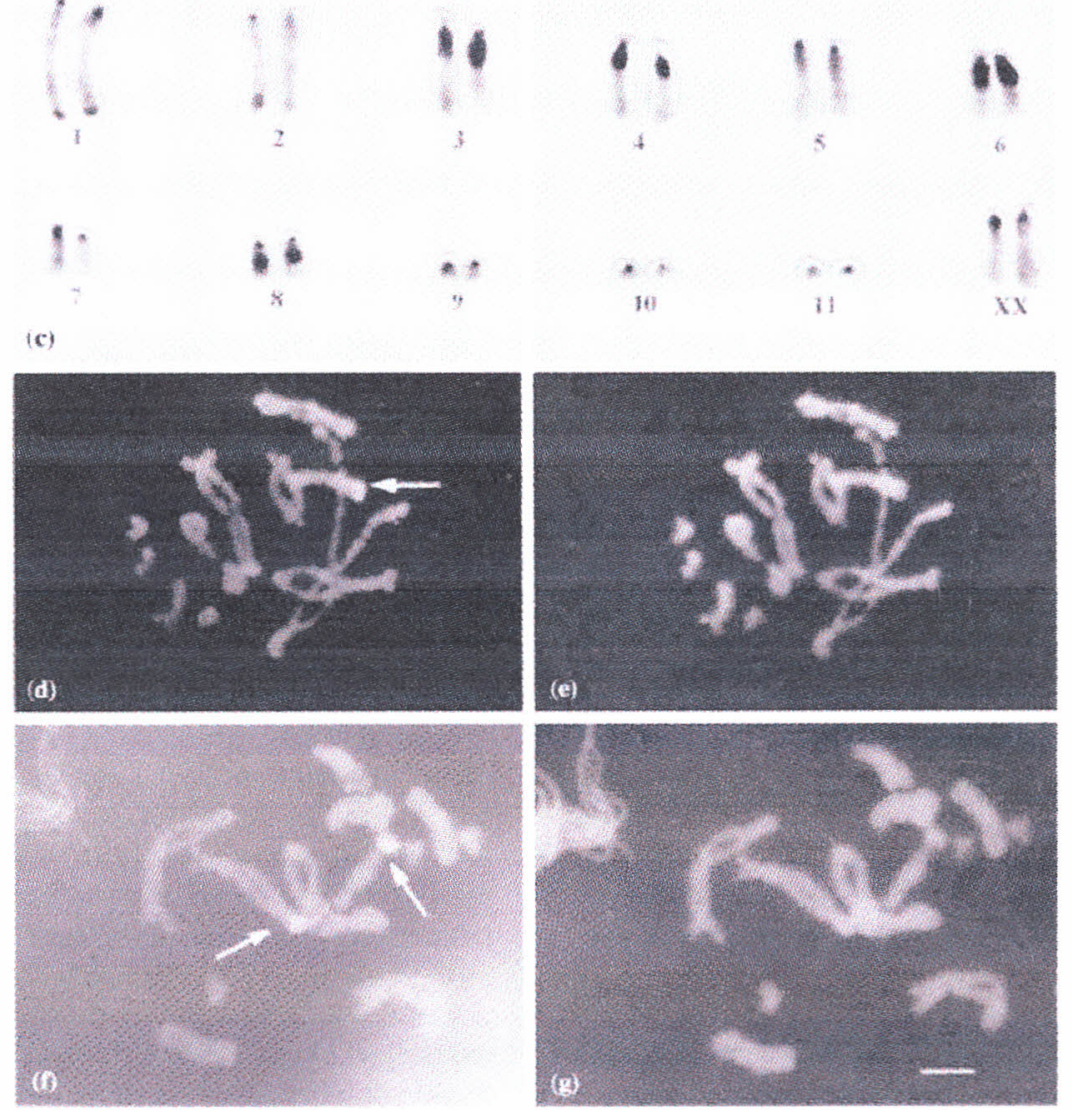

Figure 3. C-banding pattern in C. nuptialis (a) and C. speciosa (b and c). Note the $\mathrm{CH}$ blocks on the small pairs and in $\mathrm{L}_{2}$. $\mathrm{CMA}_{3}$ / DA/DAPI staining of diplotene cells from C. nuptialis ( $\mathrm{d}$ and $\mathrm{e}$ ) and C. speciosa ( $\mathrm{f}$ and $\mathrm{g}$ ). The arrows indicate the $\mathrm{CMA}_{3}^{+}$blocks. Bar $=10 \mu \mathrm{m}$.

\section{Discussion}

Karyotypes of $C$. nuptialis and $C$. speciosa resemble those reported for other Chromacris species and for most romaleid species, as to chromosome number $(2 n=23, \mathrm{X} 0$ and $2 n=24, \mathrm{XX})$ and morphology (acrocentric) (Mesa, Ferreira \& Carbonell, 1982; Souza \& Kido, 1995; Rocha,
Souza \& Tashiro, 1997). One exception to this uniformity has been described for Xestotrachelus robustus $(2 n=23, \mathrm{X} 0$ and $2 n=24, \mathrm{XX})$, a species taxonomically related to Chromacris, where the $\mathrm{S}_{9}$ and $\mathrm{S}_{10}$ pairs are meta-submetacentric and probably originated from a pericentric inversion, since the rearrangement did not change the chromosome number of the species (Souza, Haver \& 
(a)

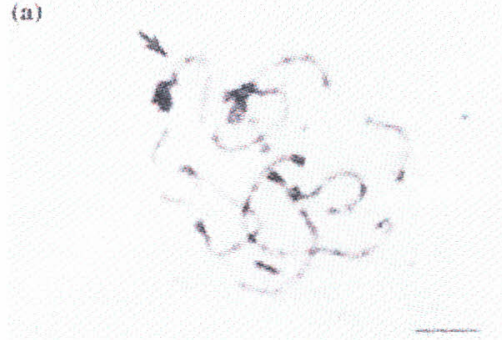

(c)
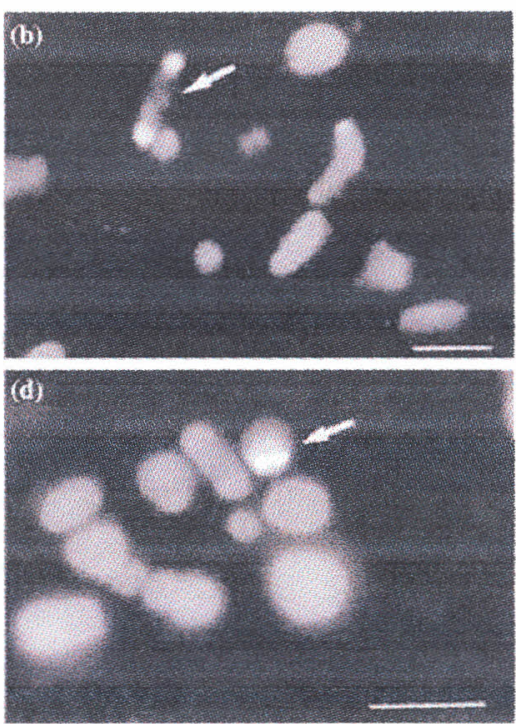

Figure 4. Identification of nucleolar organizer regions (NORs) and rDNA sites in C. nuptialis and $C$. speciosa by silver nitrate staining ( $a$ and $c$ ) and FISH ( $b$ and d), respectively. The arrows indicate the $\mathbf{M}_{6}$ pair with NORs in the pericentromeric region of C. nuptialis (a and b) and in the proximal region of $C$. speciosa (c and d). Bar $=10 \mu \mathrm{m}$.

Melo, 2003). Indeed, romaleid species have shown a highly conserved karyotype, with only a few cases of rearrangements being known (X-autosome and autosome-autosome fusion), what lead to a reduction in chromosome number (Mesa, Ferreira \& Carbonell, 1982).

Cellular events as paracentric inversion (Koehler et al., 2002), cohesion loss among chromatidsisters (Cimini et al., 2003) and failure in the checkpoint of the metaphase/anaphase control (LeMaire-Adkins, Radke \& Hunt, 1997) has been described in some organisms. However, the detailed analysis of meiotic aberrations in $C$. nuptialis does not seem to indicate any of those events. A possible explanation for the abnormalities would be that the sticky among homologous chromatids to the block of $\mathrm{CH}$ of $\mathrm{L}_{2}$ is maintained by proteins connection in the heterochromatin. Stickness has been described in polytene chromosomes of Drosophila and Chironomus, in mitotic chromosomes of maize callus culture (Fluminhan, Aguiar-Perecin \& Dos Santos, 1996) and in Ornithogalum longibracteatum (Pedrosa et al., 2001), where the existence of proteic factors, associated with $\mathrm{CH}$, was admitted.

The karyotype similarity detected by conventional analysis between romaleid species was not observed when comparing $\mathrm{CH}$ patterns. No similar pattern has been identified between the few species studied thus far. Despite a predominance of pericentromeric $\mathrm{CH}$, a wide variability in size, block locations (telomeric, interstitial and proximal) and the presence of an extra $\mathrm{CH}$ as supernumerary segments and B chromosomes, have been reported (Vilardi, 1986; Souza \& Kido, 1995; Rocha, Souza \& Tashiro, 1997; Pereira \& Souza, 2000; Souza, Haver \& Melo, 2003). When CH patterns of $C$. nuptialis and $C$. speciosa were compared with those of Xestotrachelus robustus, a closer similarity was observed between $C$. nuptialis and $X$. robustus due to the predominance of pericentromeric $\mathrm{CH}$. However, differences were detected in the small pairs. Whereas $C$. nuptialis possesses an interstitial block in $\mathbf{S}_{9}$, a telomeric in $S_{10}$ and a pericentromeric one in $S_{11}$, in $X$. robustus the $S_{9}$ and $S_{10}$ chromosomes are entirely heterochromatic (Souza, Haver \& Melo, 2003). Chromacris speciosa showed even a more particular pattern consisting of large pericentromeric $\mathrm{CH}$ blocks, on the large and medium bivalents, and a diversity of proximal, telomeric and interstitial blocks. This divergence of C-banding pattern in Chromacris indicates that heterochromatin rearrangements (amplification for example) may be involved in the karyotypic evolution of the group.

Comparison of the results obtained by $\mathrm{CMA}_{3} /$ DA/DAPI staining for $C$. nuptialis and $C$. speciosa 
also revealed some differences. Chromacris nuptialis had only one $\mathrm{CMA}_{3}^{+}$pericentromeric block, while two blocks (a proximal and a telomeric one) were observed in C. speciosa. This scarcity of GC base pairs in $\mathrm{CH}$ contrasts with data reported for other romaleid species, in which $\mathrm{CMA}_{3}^{+}$blocks predominate (Souza, Rufas \& Orellana, 1998; Pereira \& Souza, 2000; Souza, Haver \& Melo, 2003). John et al. (1985), analyzing ten Australian acridid grasshoppers, identified distinct classes of $\mathrm{CH}$, when cytological preparations of these species were stained with $\mathrm{CMA}_{3}$ and DAPI fluorochromes. In Recitropis sp.1 a part of $\mathrm{CH}$ was $\mathrm{CMA}_{3}^{+}$, while the other was homogenous for these fluorochromes. On the other hand, Ursina sp. showed three classes, $\mathrm{CMA}_{3}^{+}, \mathrm{DAPI}^{+}$and a third one without specificity. Two categories of $\mathrm{CH}$ could be distinguished in the species analyzed here, one GC-rich and the other, a more frequent, one without any specific richness.

The location of NORs in representatives of the Romaleidae family can be divided into three categories: those restricted to autosomes, as observed in Xestotrachelus robustus (pericentromeric region of $\mathrm{M}_{5}$ ) (Souza, Haver \& Melo, 2003), Radacridium nordestinum (interstitial region of the $\mathrm{L}_{2}$ bivalent) (Rocha, Souza \& Tashiro, 1997) and Phaeoparia megacephala (proximal region of $\mathbf{M}_{6}$ ) (Pereira \& Souza, 2000); those located on the sex chromosome, as in Radacridium mariajoseae (proximal site of the X) (Rocha, Souza \& Tashiro, 1997); and those with NORs on both autosomes and allosomes, as in Xyleus angulatus, with proximal sites on the $\mathrm{L}_{3}$ and $\mathrm{M}_{4}$ bivalents and the $\mathrm{X}$ chromosome (Souza, Rufas \& Orellana, 1998).

Chromacris nuptialis and C. speciosa had only one nucleolar organizer pair, as observed for most romaleid species analyzed, but they differed in terms of the NOR position, which was pericentric in C. nuptialis and proximal in C. speciosa. Since the NOR is located on the same pair $\left(\mathrm{M}_{6}\right)$ in those species, we may suppose that some event (paracentric inversion, heterochromatin amplification or unequal crossing-over) might have led to the modification of the original pericentric position to the proximal one, observed in $C$. speciosa during the course of its evolution. Paracentric inversion was hyphothesized as the rearrangement involved in karyotypes differences for NORs location in two fish species. The location was in pericentromeric and subtelomeric region, in Umbra pygmaea and $U$. limi, respectively (Rab et al., 2002). Moreover, amplification was pointed out as the first event, in the different NORs location in Triticeae genomes (Dubcovsky \& Dvorak, 1995).

FISH using $45 \mathrm{~S}$ rDNA probe confirmed the existence of only one nucleolar organizer pair in the two species and helped to clarify the position of rDNA sites, which are sometimes hidden by nucleolar remnants, when visualized by silver nitrate. This result is similar to the one reported by Souza, Haver and Melo (2003) for X. robustus showing only one sign on $\mathrm{M}_{5}$ pair. Since FISH coincided with the proximal region of the $\mathbf{M}_{6}$ bivalent $\left(\mathrm{CMA}_{3}^{+}\right)$of $C$. speciosa, and no sign was observed in the $\mathrm{CMA}_{3}^{+}$telomeric region of $\mathrm{L}_{2}$, the $\mathrm{CH}$ in this region, although GC-rich, is likely to show no functional relationship with rDNA sites, and it might be organized differentially from the other $\mathrm{CH}$ regions.

Our results indicated a significant degree of chromosome differentiation between $C$. nuptialis and $C$. speciosa, when comparing the distribution pattern and composition of $\mathbf{C H}$, as well as the position of the rDNA sites. The karyotype differences observed indicate a distinction in taxonomic status between species, confirming the analysis of some morphological traits, performed by Roberts and Carbonell (1982), who demonstrated that $C$. nuptialis is not a variant form of C. speciosa. However, only cytogenetic and molecular analysis of other members of colorata and trogon groups will determine whether the differences observed are frequent among these representatives, or whether C. speciosa and $C$. nuptialis can be included in distinct groups.

\section{Acknowledgements}

We are very grateful to Dr Carlos S. Carbonell, Montevideo University, for the taxonomic identification of the species and Prof Dr Marcelo Guerra for laboratory facilities for FISH experiment and for his opinion and valuable comments on the manuscript. The authors also grateful to Dr Neide Santos, Dr Rita de Cássia de Moura and Dr Aline Alexandrino for helpful suggestions and the revision of the manuscript. To Francisca Tavares for technical support. This research was supported by CAPES (Coordenação de Aperfeiçoamento de Pessoal de Nível Superior), 
CNPq (Conselho Nacional de Desenvolvimento Científico e Tecnológico) and FACEPE (Fundação de Amparo à Ciência do Estado de Pernambuco). Eva Stadtler was student of scientific initiation (PIBIC/CNPq).

\section{References}

Bella, J.L., J. Gosálvez, R.A. Nichols, C. López-Fernández C. García de la Vega \& G.M. Hewitt, 1990. Chromosome divergence in Podisma Berthold through the Alps, Pyrenees and Sistema Ibérico. Bol. San. Veg. Plagas 20: 349-358.

Bridle, J.R., J. de la Torre, J.L. Bella, R.K. Butlin \& J. Gosálvez, 2002. Low levels of chromosomal differentiation between the grasshoppers Chorthippus brunneus and Chorthippus jacobsi (Orthoptera;Acrididae) in northern Spain. Genetica 114: 121-127.

Camacho, J.P.M. \& J. Cabrero, 1983. Karyological diferences between two species of grasshopper genus Acrotylus (Acrididae: Oedipodinae). Caryologia 36: 121-127.

Cimini, D., M. Mattiuzzo, L. Torosantucci \& F. Degrassi, 2003. Histone hyperacetylation in mitosis prevents sister chromatid separation and produces chromosome segregation defects. Mol. Biol. Cell 14: 3821-3833.

Dubcovsky, J. \& J. Dvorak, 1995. Ribossomal RNA multigene loci: nomads of the Triticeae genomes. Genetics 140; 1367 1377.

Fluminhan, Jr., A., M.L.R. Aguiar-Perecin \& J.A. Dos Santos, 1996. Evidence for heterochromatin involvement in chromosome breakage in maize callus culture. Ann. Bot. 78: 7381.

John, B., M. King, D. Schweizer \& M. Mendelak, 1985. Equilocality of heterochromatin distribution and heterochromatin heterogeneity in acridid grasshoppers. Chromosoma 91: 185-200.

Koehler, K.E., E.A. Millie, J.P. Cherry, P.S. Burgoyne E.P. Evans, P.A. Hunt \& T.J. Hassold, 2002. Sex-specific differences in meiotic chromosome segregation revealed by dicentric bridge resolution in mice. Genetics 162: 13671379

LeMaire-Adkins, R., K. Radke \& P.A. Hunt, 1997. Lack of checkpoint control at the metaphase/anaphase transition: A mechanism of meiotic nondisjunction in mammalian females. J. Cell Biol. 139: 1611-1619.

Mesa, A., A. Ferreira \& C.S. Carbonell, 1982. Cariologia de los acridoideos neotropicales: estado actual de su conocimento y nuevas contribuciones. Ann. Soc. Ent. Fr. (N. S.) 18: 507 526.

Moscone, E.A., M.A. Matzke \& A.J.M. Matzke, 1996. The use of combined FISH/GISH in conjunction with DAPI counterstaining to identify chromosomes containing transgene inserts in amphidiploid tobacco. Chromosoma 105: 231-236.

Pedrosa, A., M.F. Jantsch, E.A. Moscone, P.F. Ambros \& D. Schweizer, 2001. Characterisation of pericentromeric and sticky intercalary heterochromatin in Ornithogalum longibracteatum (Hyacinthaceae). Chromosoma 110: 203213.

Pereira, L.G. \& M.J. Souza, 2000. Nature and distribution of constitutive heterochromatin and NOR location in the grasshopper Phaeoparia megacephala (Romaleidae: Orthoptera). Cytobios 103: 111-119.

Rab, P., E.J. Crossman, K.M. Reed \& M. Rabova, 2002. Chromosomal characteristics of ribosomal DNA in two extant species of North American mudminnows Umbra pygmaea and $U$. limi (Euteleostei: Umbridae). Cytogenet. Genome Res. 98: 194-198.

Roberts, H.R. \& C.S. Carbonell, 1982. A revision of thr grasshopper genera Chromacris and Xestotrachelus (Orthoptera, Romaleidae, Romaleinae). Proc. Calif. Acad. Sci. 43: $43-58$.

Rocha, M.F., M.J. Souza \& T. Tashiro, 1997. Karyotype variability in the Genus Radacrilium (OrthopteraRomaleidae). Cytologia 62: 53-60.

Rodríguez-Iñigo, E., J.L. Bella \& C. García de la Vega, 1993. Heterochromatin diferentiation between two species of the genus Dociostaurus (Orthoptera: Acrididae). Heredity 70 : $458-465$.

Rufas, J.S., P. Esponda \& J. Gosálvez, 1985. NOR and nucleolus in the spermatogenesis of acridoid grasshoppers. Genetica 66: 139-144.

schweizer, D., M. Mendelak, M.J.D. White \& N. Contreras, 1983. Cytogenetics of the parthenogenetic grasshopper Warramaba virgo and its bisexual relatives. X. Pattern of fluorescent banding. Chromosoma 88: 227-236.

Souza, M.J. \& M.H.N. Silva-Filha, 1993. Effects of extra chromosome segments on chiasma distribution in Xyleus angulatus (Orthoptera, Romaleidae). Rev. Brasil. Genet. 16: 23-33.

Souza, M.J. \& L.M.H. Kido, 1995. Variability of constitutive heterochromatin in karyotypes of representatives of the family Romaleidae (Orthoptera). Rev. Brasil. Genet. 18: 517-520.

Souza, M.J., J.S. Rufas \& J. Orellana, 1998. Constitutive heterochromatin, NOR location and FISH in the grasshopper Xyleus angulatus (Romaleidae). Caryologia 51: $73-$ 80.

Souza, M.J., P.R.O. Haver \& N.F. Melo, 2003. Karyotype, C- and fluorescence banding patterns, NOR location and FISH in the grasshopper Xestotrachelus robustus (Romaleidae). Caryologia 56: 261-267.

Sumner, A.T., 1972. A simple technique for demonstrating centromeric heterochromatin. Exp. Cell Res. 75: 304 306.

Unfried, I., U. Stocker \& P. Gruendler, 1989. Nucleotide sequence of the 18S rRNA genes from Arabidopsis thatiana. Nucleic Acids Res. 17: 7513.

Unfried, I. \& P. Gruendler, 1990. Nucleotide sequence $5.8 \mathrm{~S}$ and 25S rRNA genes and of the internal spacers from Arabidopsis thaliana. Nucleic Acids Res. 18: 4011.

Vilardi, J.C., 1986. Parallel polymorphism for intersticial C-bands and B-chromosomes in Zoniopoda tar sata (Orthoptera-Romaleidae). Caryologia 39: 365-380. 